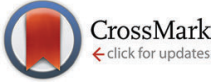

Cite this: J. Mater. Chem. C, 2015 3, 11202

Received 20th August 2015 Accepted 28th September 2015 DOI: $10.1039 / c 5 t c 02583 d$

www.rsc.org/MaterialsC

\section{Amphotropic azobenzene derivatives with oligooxyethylene and glycerol based polar groups $\uparrow$}

\author{
Xiaoping Tan,,$^{\mathrm{a}}$ Ruilin Zhang, $\neq^{\mathrm{ab}}$ Chunxiang Guo, ${ }^{a}$ Xiaohong Cheng, ${ }^{* a}$ \\ Hongfei Gao, ${ }^{a}$ Feng Liu, ${ }^{\star c}$ Johanna R. Bruckner, ${ }^{d}$ Frank Giesselmann, ${ }^{\text {d }}$ \\ Marko Prehm ${ }^{e}$ and Carsten Tschierske* ${ }^{*}$
}

\begin{abstract}
A series of amphiphilic azobenzenes with one to three lipophilic alkyl chains at one end and polar groups with oligooxyethylene (EO) and racemic 3-glyceryl units at the opposite end was synthesized and their thermotropic and lyotropic liquid crystalline self-assemblies were studied by POM, DSC and XRD. Tilted and non-tilted lamellar phases with interdigitated double layer structures $\left(\mathrm{SmC}_{d}\right.$ and $\mathrm{SmA}_{d}$ respectively) were found for the compounds with a single alkyl chain, whereas hexagonal columnar phases were formed by the compounds with two or three alkyl chains. The effect of protic solvents, like formamide, ethylene glycol and water, was investigated for representative examples. For the compounds with the single chain, induction and stabilization of SmA phases were observed, though broad regions of lyotropic SmC phases were retained in most cases. Depending on the structure of the polar group, the hexagonal columnar phases were either removed or drastically stabilized by the solvents. Photoisomerisation of an azobenzene chromophore was also studied.
\end{abstract}

\section{Introduction}

Design of molecules which can self-assemble into ordered nanostructures is of current interest for the general understanding of the processes of molecular self-assembly. ${ }^{1}$ Amphiphilic and anisometric compounds have aroused special interest as they can organize into ordered liquid crystalline (LC) superstructures with surprising complexity and great interest for materials science as well as life science. ${ }^{2}$ By combining an anisometric molecular shape and an amphiphilic structure, both representing structural concepts supporting LC self-assembly, new amphotropic molecules can be obtained. ${ }^{3-5}$ Such molecules can display thermotropic and lyotropic LC phases and form well defined monolayers at interfaces. ${ }^{12}$ Typical examples are amphotropic LCs involving

\footnotetext{
${ }^{a}$ Key Laboratory of Medicinal Chemistry for Natural Resources, Chemistry Department, Yunnan University, Kunming, Yunnan 650091, P. R. China.

E-mail: xhcheng@ynu.edu.cn; Fax: +86 8715032905

${ }^{b}$ Forensic Medicine of Kunming Medical University, Kunming 650500, P. R. China

${ }^{c}$ State Key Laboratory for Mechanical Behavior of Materials, Xi'an Jiaotong University, Xi'an, 710049, P. R. China. E-mail:feng.liu@mail.xjtu.edu.cn; Fax: +86 2982663453

${ }^{d}$ University of Stuttgart, Institute of Physical Chemistry, Pfaffenwaldring 55, D-075069, Stuttgart, Germany. E-mail: f.giesselmann@ipc.uni-stuttgart.de; Fax: +49 711-685-62569

${ }^{e}$ Institute of Chemistry, Organic Chemistry, Martin Luther University Halle-Wittenberg, Kurt-Mothes Str. 2, 06120 Halle/Saale, Germany.

E-mail: carsten.tschierske@chemie.uni-halle.de; Fax: +49345 5527346

$\dagger$ Electronic supplementary information (ESI) available. See DOI: 10.1039/ c5tc02583d

$\ddagger$ Both authors contributed equally to this work.
}

biphenyl, ${ }^{6-8}$ phenylpyrimidine ${ }^{9,10}$ and other rigid cores ${ }^{11,12}$ terminated with alkyl chains at one end and oligooxyethylene (EO) or glycerol-based groups at the other end. ${ }^{5}$ Amphotropic LCs involving EO chains and glycerol units are potentially useful, for example, for design of nanostructured $1 \mathrm{D}, 2 \mathrm{D}$ or $3 \mathrm{D}$ ion conducting materials in combination with ionic liquids. ${ }^{13}$ On the other hand, LC azobenzene derivatives have attracted attention because of their photoresponsive properties caused by the trans-cis photoisomerization of the azobenzene units. ${ }^{14}$ Therefore, a wide diversity of azobenzene derivative LCs have been designed to introduce light-modulated functionalities, for example for application as organic light-driven actuators. ${ }^{15,16}$ Photoisomerizable amphiphiles can find applications in photoswitchable surfactants, ${ }^{17}$ for drug delivery, ${ }^{18}$ switchable vesicles ${ }^{19}$ and controlled gelation. ${ }^{20}$ Considering the vast variety of useful properties and potential applications, photoswitchable azobenzene based amphiphiles ${ }^{21-27}$ and especially photoswitchable amphotropic $\mathrm{LCs}^{28-30}$ have received comparatively little attention to date. Herein we report the design, synthesis and thermotropic as well as lyotropic liquid crystalline self-assembly of new amphiphilic azobenzenes, consisting of $\mathrm{EO}^{31}$ or glycerol based polar groups or combinations of both involving one or two hydroxyl groups in the polar groups, and having one to three lipophilic $n$-alkyl chains at the opposite end.

In the notation of the compounds $1-3\left(1^{n} \mathbf{E O}^{m} \mathbf{O H}\right.$ to $3^{n} \mathbf{E O} \mathbf{O}^{m} \mathbf{O H}$ and $\mathbf{1}^{n} \mathbf{E O}^{m}(\mathbf{O H})_{2}$ to $3^{n} \mathbf{E O}^{m}(\mathbf{O H})_{2}$, see Scheme 1), the first number indicates the number of terminal $n$-alkyl chains and the superscript $n$ represents the length of these chains. Note that in compounds of 


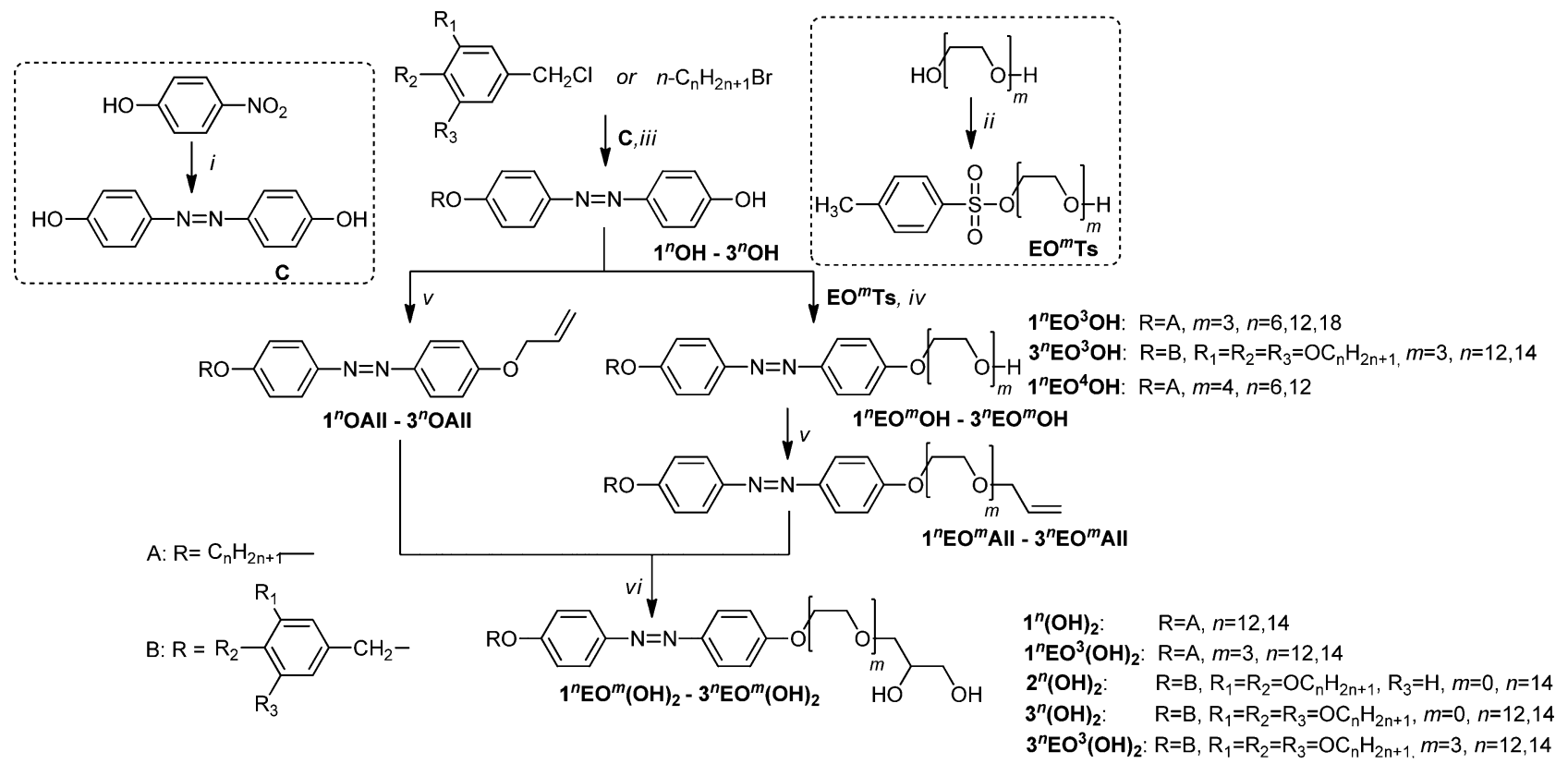

Scheme 1 Synthesis of compounds 1-3. Reagents and conditions: (i) $\mathrm{KOH}, \mathrm{H}_{2} \mathrm{O}, 195-200{ }^{\circ} \mathrm{C}, 5 \mathrm{~h}$; (ii) $\mathrm{TsCl}_{1} \mathrm{CH}_{2} \mathrm{Cl}_{2}, \mathrm{Et}_{3} \mathrm{~N}, 0-25{ }^{\circ} \mathrm{C}$; (iii) $\mathrm{K}_{2} \mathrm{CO}_{3}, \mathrm{DMF}$, $90{ }^{\circ} \mathrm{C}, 12 \mathrm{~h}$; (iv) $\mathrm{CH}_{3} \mathrm{CN}, \mathrm{K}_{2} \mathrm{CO}_{3}, 70{ }^{\circ} \mathrm{C}, 24 \mathrm{~h}$; (v) allyl bromide, $\mathrm{NaH}, \mathrm{THF}, 70{ }^{\circ} \mathrm{C}, 12 \mathrm{~h}$; (vi) OsO $\mathrm{O}_{4}, \mathrm{NMMNO}, \mathrm{H}_{2} \mathrm{O}$, acetone, $25^{\circ} \mathrm{C}, 24 \mathrm{~h}$.

type 1 the single alkoxy chain is directly attached to the azobenzene core whereas for compounds of types $\mathbf{2}$ and $\mathbf{3}$ with more than only one alkoxy chain these chains are attached via an additional benzylether unit to the azobenzene core. EO indicates the presence of an EO chain with a number $m$ of EO units in this chain. At the end $\mathrm{OH}$ denotes the presence of a single terminal hydroxyl group, whereas $(\mathrm{OH})_{2}$ indicates a racemic 3-glyceryl unit. Compounds $\mathbf{1}^{n}(\mathbf{O H})_{2}-3^{n}(\mathbf{O H})_{2}$ have the 3-glyceryl units directly connected to the azobenzene core by an ether linkage.

\section{Results and discussion}

\subsection{Synthesis}

The synthesis of the compounds under discussion is shown in Scheme 1 . The key intermediate is azobenzene-4,4'-diol $\mathbf{C}$, which was prepared based on the method of Willstätter and Benz from 4-nitrophenol ${ }^{32}$ and monoalkylated with appropriate $n$-bromoalkanes or monobenzylated with alkoxysubstituted benzyl chlorides, leading to the $4^{\prime}$-alkoxysubstituted azobenzene-4-ols $\mathbf{1}^{n} \mathbf{O H}$ and the $4^{\prime}$-benzyloxy-azobenzene-4-ols $2^{\mathbf{1 4}} \mathbf{O H}$ and $3^{n} \mathbf{O H}$, respectively. Compounds $\mathbf{1}^{n} \mathbf{O H}$ and $3^{n} \mathbf{O H}$ were alkylated using tri- and tetraethylene glycol monotosylates $\mathbf{E O}^{\boldsymbol{m}}$ Ts yielding compounds $\mathbf{1}^{n} \mathbf{E} \mathbf{O}^{m} \mathbf{O H}$ and $3^{n} \mathbf{E} \mathbf{O}^{m} \mathbf{O H}$. These compounds and the azobenzene-4-ols $\mathbf{1}^{n} \mathbf{O H}-3^{n} \mathbf{O H}$ were etherified with allylbromide, followed by dihydroxylation of the double bonds using $\mathrm{OsO}_{4} / N$-methylmorpholine- $N$-oxide (NMMNO). ${ }^{33}$ The obtained target compounds, the alcohols $\mathbf{1}^{n} \mathbf{E} \mathbf{O}^{m} \mathbf{O H}$ and $3^{n} \mathbf{E} \mathbf{O}^{m} \mathbf{O H}$ and the glycerol ethers $2^{\mathbf{1 4}}(\mathbf{O H})_{2}, 3^{n}(\mathbf{O H})_{2}$ and $3^{n} \mathbf{E O}^{m}(\mathbf{O H})_{2}$ were purified by column chromatography or crystallization from ethyl acetate. Detailed synthetic procedures and analytical data are given in the ESI. $\dagger$

\subsection{Thermotropic self-assembly of the single chain compounds 1 in SmA and SmC phases}

The phase transition temperatures and enthalpies of the azobenzene derivatives with a single alkyl chain (compounds 1) are listed in Tables 1 and 2. No LC phases were found for the EO ethers with only one $\mathrm{OH}$ group and comparatively short hexyl chains (compounds $\mathbf{1}^{\mathbf{6}} \mathbf{E} \mathbf{O}^{\mathbf{m}} \mathbf{O H}$ with $m=3$, 4). Elongation of the alkyl chain leads to SmC phases. All compounds with terminal glycerol groups show smectic phases with enhanced stability compared to the compounds with only a single $\mathrm{OH}$ group. Among them, compounds $\mathbf{1}^{\mathbf{n}}(\mathbf{O H})_{2}$ without EO units have enhanced mesophase stability compared to the related compounds $\mathbf{1}^{n} \mathbf{E O}^{\boldsymbol{m}}(\mathbf{O H})_{2}$ with additional EO units. SmC phases were found in all cases and for most compounds with glycerol groups, additional

Table 1 Mesophases, transition temperatures $\left(T /{ }^{\circ} \mathrm{C}\right)$ and transitional enthalpy values $\left(\Delta H / \mathrm{kJ} \mathrm{mol}^{-1}\right)$ of the single chain compounds $1^{n} \mathrm{EO}^{m} \mathrm{OH}$ with a single $\mathrm{OH}$ group ${ }^{a}$

\begin{tabular}{|c|c|c|c|}
\hline \multicolumn{4}{|c|}{$1^{n} \mathrm{EO}^{m} \mathrm{OH}$} \\
\hline Comp & $\mathrm{R}_{1}$ & $m$ & Phase transitions \\
\hline$\overline{1^{6} \mathrm{EO}^{3} \mathrm{OH}}$ & $\mathrm{C}_{6} \mathrm{H}_{13} \mathrm{O}$ & 3 & Cr 102 [51.5] Iso \\
\hline $1^{6} \mathrm{EO}^{4} \mathrm{OH}$ & $\mathrm{C}_{6} \mathrm{H}_{13} \mathrm{O}$ & 4 & Cr 104 [49.5] Iso $^{b}$ \\
\hline $1^{12} \mathrm{EO}^{3} \mathrm{OH}$ & $\mathrm{C}_{12} \mathrm{H}_{25} \mathrm{O}$ & 3 & Cr 97 [35.6] $\mathrm{SmC}_{\mathrm{d}} 106$ [12.3] Iso \\
\hline $1^{12} \mathrm{EO}^{4} \mathrm{OH}$ & $\mathrm{C}_{12} \mathrm{H}_{25} \mathrm{O}$ & 4 & Cr $96[42.6] \mathrm{SmC}_{\mathrm{d}} 113$ [16.5] Iso \\
\hline $1^{18} \mathrm{EO}^{3} \mathrm{OH}$ & $\mathrm{C}_{18} \mathrm{H}_{37} \mathrm{O}$ & 3 & Cr 106 [52.1] $\mathrm{SmC}_{\mathrm{d}} 114$ [16.1] Iso \\
\hline
\end{tabular}

${ }^{a}$ Transition temperature and enthalpy changes (in square brackets) were determined by DSC (peak temperature, first heating scan, $10^{\circ} \mathrm{C} \mathrm{min}^{-1}$ ); abbreviations: $\mathrm{Cr}=$ crystalline solid; $\mathrm{SmC}_{\mathrm{d}}=$ tilted smectic phase with a double layer structure; Iso $=$ isotropic liquid state. ${ }^{b}$ Supercooling was possible to $95{ }^{\circ} \mathrm{C}$. 
Table 2 Mesophases, transition temperatures $\left(T /{ }^{\circ} \mathrm{C}\right)$ and transitional enthalpy values $\left(\Delta H / \mathrm{kJ} \mathrm{mol}^{-1}\right)$ of the single chain compounds $1^{n}(\mathrm{OH})_{2}$ and $1^{n} \mathrm{EO}^{m}(\mathrm{OH})_{2}$ with a racemic 3-glyceryl group ${ }^{a}$

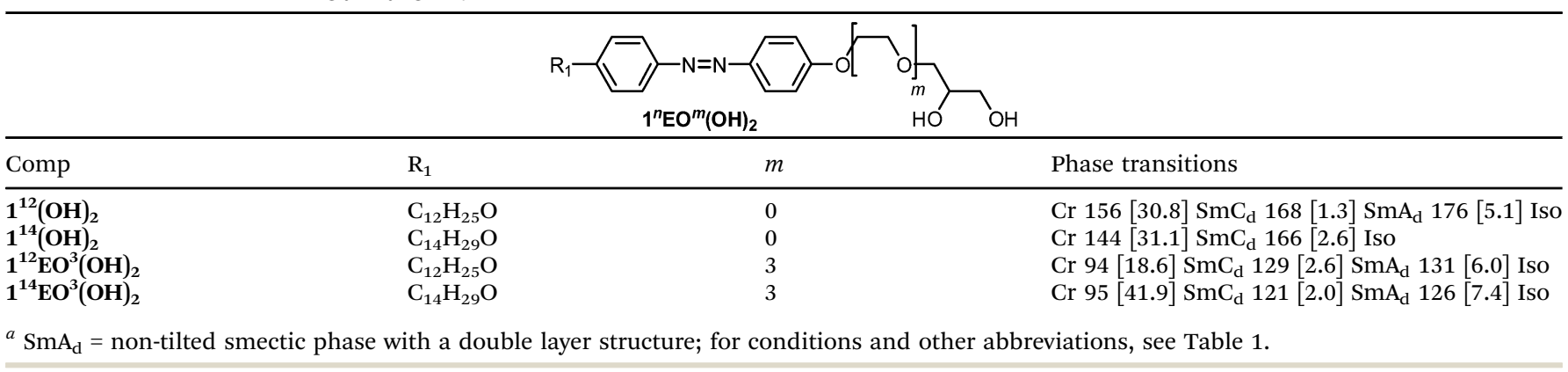

SmA phases are formed above the SmC phases. The SmA-SmC transitions have comparatively large enthalpy values $(\Delta H=1.3-$ $2.6 \mathrm{~kJ} \mathrm{~mol}^{-1}$ ) for this kind of transition and thus this phase transitions appear to be first order. Fig. 1 shows representative DSC traces for compound $\mathbf{1}^{\mathbf{1 2}}(\mathbf{O H})_{2}$ with a SmC-SmA sequence. Interestingly, the Sm-Iso transition enthalpy values of the glycerol derivatives, having two terminal $\mathrm{OH}$ groups, are only about one half of those of the amphiphiles with only one hydroxyl group (compare Tables 1 and 2), which is discussed later.

By microscopic investigation between non-treated glass plates through crossed polarizers, the smectic $\mathrm{C}$ phases of these compounds occur with typical broken fan and SmC schlieren textures $^{34-36}$ (see Fig. 2a) and the SmA phases are characterized by focal-conic fan-like textures and pseudoisotropic regions (Fig. 2b), often separated by oily streaks.

Compounds $\mathbf{1}^{12} \mathbf{E O}^{3} \mathbf{O H}$ and $\mathbf{1}^{12}(\mathbf{O H})_{2}$ were investigated as representative examples by X-ray diffraction (XRD; see Fig. 3). Diffuse wide angle scattering with maxima at $d=0.45-0.47 \mathrm{~nm}$, corresponding to the mean lateral distance between the molecules, indicate fluid smectic phases without in-plane order for all investigated compounds. This excludes the presence of other low temperature smectic mesophases ${ }^{37}$ and thus assignment to SmA and SmC was confirmed by XRD. The sharp fundamental

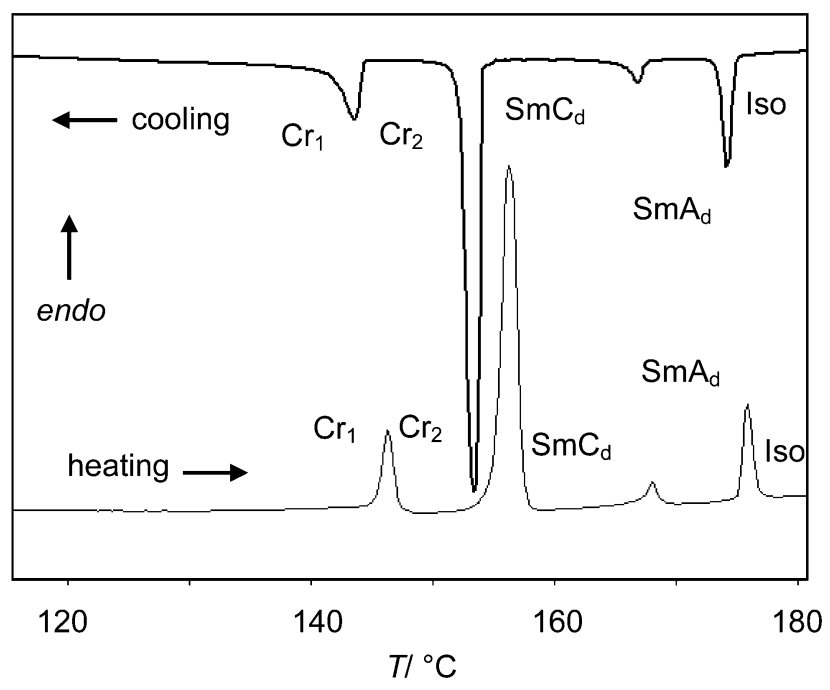

Fig. 1 DSC traces of $\mathbf{1}^{12}(\mathrm{OH})_{2}\left(10 \mathrm{~K} \mathrm{~min}^{-1}\right)$.
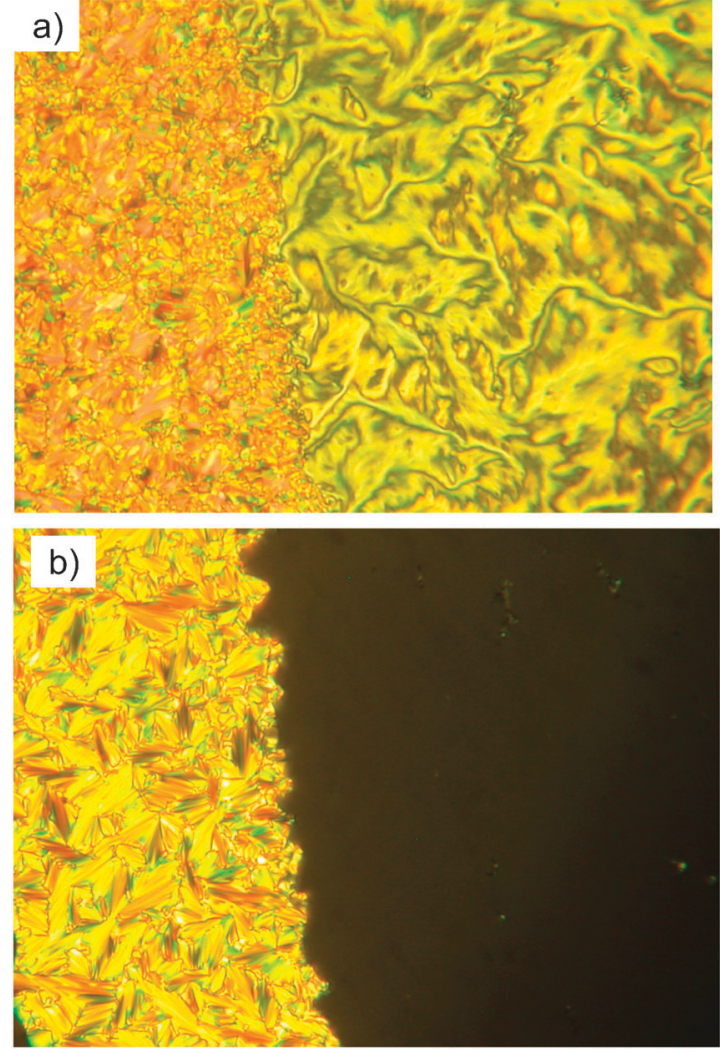

Fig. 2 Textures of $\mathbf{1}^{12}(\mathrm{OH})_{2}$ in the (a) $\mathrm{SmC}_{d}$ phase at $T=167^{\circ} \mathrm{C}$ and (b) in the $\mathrm{SmA}_{d}$ phase at $T=169{ }^{\circ} \mathrm{C}$ as observed upon heating; at the right homeotropic alignment and at the left predominately planar alignment with fan texture.

and second-order pseudo-Bragg peaks in the small-angle regime originate from the long-range lamellar order along a single direction. For compound $\mathbf{1}^{\mathbf{1 2}} \mathbf{E} \mathbf{O}^{\mathbf{3}} \mathbf{O H}$ the layer reflection has a tilt angle of $\theta=29^{\circ}$ with respect to the maxima of the diffuse wide angle scattering, indicating the presence of a synclinic SmC phase with an average tilt angle of $29^{\circ}$ (see Fig. 3c). The layer spacing is $d=5.57 \mathrm{~nm}$ while the length of the molecule is only $L_{\max }=3.7 \mathrm{~nm}$ (calculated by the MM2 method ${ }^{38}$ and assuming a molecule in the most stretched conformation with all-trans conformation for the alkyl chains and EO chains ${ }^{39}$ ). Thus the layer thickness is significantly larger than the molecular length $(d / L=1.5)$. Considering the tilt, the effective molecular length is 

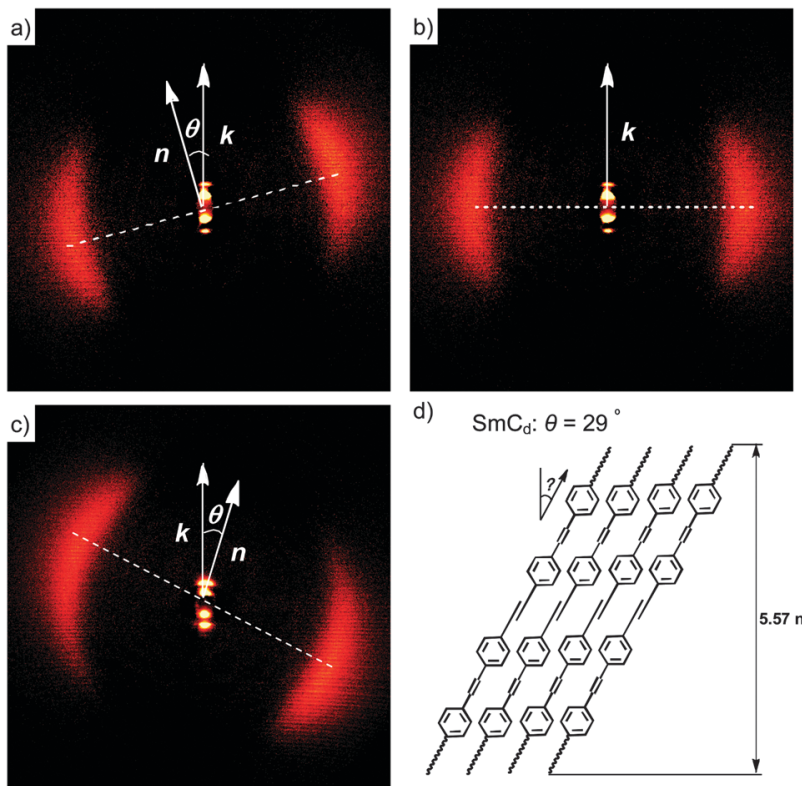

d) $\mathrm{SmC}_{\mathrm{d}}: \theta=29$

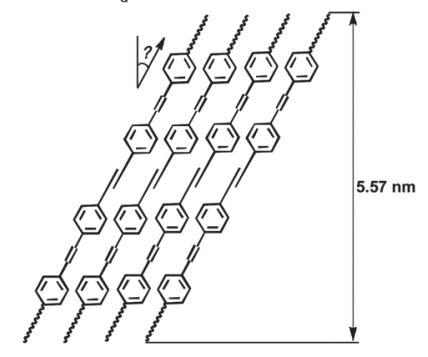

Fig. 3 XRD patterns of the smectic phases after subtraction of the scattering in the isotropic liquid states: (a) 2D-XRD pattern of a surface aligned sample of compound of $\mathbf{1}^{12}(\mathrm{OH})_{2}$ in the $\mathrm{SmC}_{d}$ phase at $T=167^{\circ} \mathrm{C}$ and (b) in the $S m A_{d}$ phase at $T=169{ }^{\circ} \mathrm{C}$ and (c) $2 \mathrm{D}$ pattern of a surface aligned sample of the $\mathrm{SmC}$ phase of $1^{12} \mathrm{EO}^{3} \mathrm{OH}$ at $T=105^{\circ} \mathrm{C}$; (d) shows a model of the molecular organization in one layer of the double layer SmC phase with partial intercalation of the alkyl chains; complete intercalation would lead to $d \sim 5.2 \mathrm{~nm}$. For additional crystallographic data, see Tables S1-S3 (ESI†).

reduced to $\cos 29^{\circ} L_{\mathrm{mol}}=3.24 \mathrm{~nm}$, leading to the effective $d / L$ ratio of 1.72 . This means that the layer distance is quite a bit smaller than twice the effective molecular length, indicating a bilayer structure with a partial intercalation of the alkyl chains as shown in Fig. 3d (the $\mathrm{SmC}_{\mathrm{d}}$ phase). The degree of alkyl chain intercalation could become smaller if there is strong disorder of the alkyl chains and especially of the EO chains.

In the SmC phase of the glycerol derivative $\mathbf{1}^{\mathbf{1 2}}(\mathbf{O H})_{2}$ with the same alkyl chain length, but without EO units the thickness of the smectic layers is $d=5.16 \mathrm{~nm}$ at $167{ }^{\circ} \mathrm{C}$ and the tilt angle is only $12^{\circ}$ (Fig. 3a). The layer thickness decreases to $5.05 \mathrm{~nm}$ at the transition from the SmA phase to the SmC phase at $167{ }^{\circ} \mathrm{C}$, in line with the emerging uniform tilt angle of only $12^{\circ}$. The ratio $d / L=1.56\left(L_{\max }=3.3 \mathrm{~nm}\right)$ also indicates an intercalated bilayer structure for the SmC and SmA phases $\left(\mathrm{SmC}_{\mathrm{d}}\right.$ and $\mathrm{SmA}_{\mathrm{d}}$ phases) with a degree of intercalation being very similar to that found in the $\mathrm{SmC}_{\mathrm{d}}$ phase of compound $\mathbf{1}^{\mathbf{1 2}} \mathbf{E \mathbf { O } ^ { 3 }} \mathbf{O H}$ (Table 3).

$\mathrm{XRD}$ investigation of the Iso phases occurring immediately above the smectic-Iso phase transition of compounds $\mathbf{1}^{12} \mathbf{E O}^{3}(\mathbf{O H})_{2}$ and $\mathbf{1}^{12} \mathbf{E O}^{3} \mathbf{O H}$, as shown in Fig. 4, indicates a higher intensity of the diffuse small angle scattering in the Iso phase of the glycerol derivative $\mathbf{1}^{12} \mathbf{E O}^{3}(\mathbf{O H})_{2}$ compared to $1^{12} \mathbf{E O}^{3} \mathbf{O H}$ having only one $\mathrm{OH}$ group. This indicates the formation of clusters in the Iso phase of $\mathbf{1}^{12} \mathbf{E O}^{3}(\mathbf{O H})_{2}$ which is much weaker for compound $\mathbf{1}^{12} \mathbf{E O}^{3} \mathbf{O H}$ with only one terminal $\mathrm{OH}$ group. This could contribute to the observation that the enthalpy values of the Sm-Iso transition of the glycerol substituted compounds are only one half or even less than those
Table 3 Comparison of X-ray data and molecular dimensions of selected single chain compounds 1

\begin{tabular}{llll}
\hline Comp. & Phase & $d / \mathrm{nm}\left(T /{ }^{\circ} \mathrm{C}\right)$ & $L / \mathrm{nm}$ \\
\hline $\mathbf{1}^{\mathbf{1 2}}(\mathbf{O H})_{\mathbf{2}}$ & $\mathrm{SmA}_{\mathrm{d}}$ & $5.16(169)$ & 3.3 \\
$\mathbf{1}^{\mathbf{1 2}} \mathbf{E O}^{\mathbf{3}} \mathbf{O H}$ & $\mathrm{SmC}_{\mathrm{d}}$ & $5.05(167)$ & 3.3 \\
& $\mathrm{SmC}_{\mathrm{d}}$ & $5.57(105)$ & 3.7 \\
\hline
\end{tabular}

a)
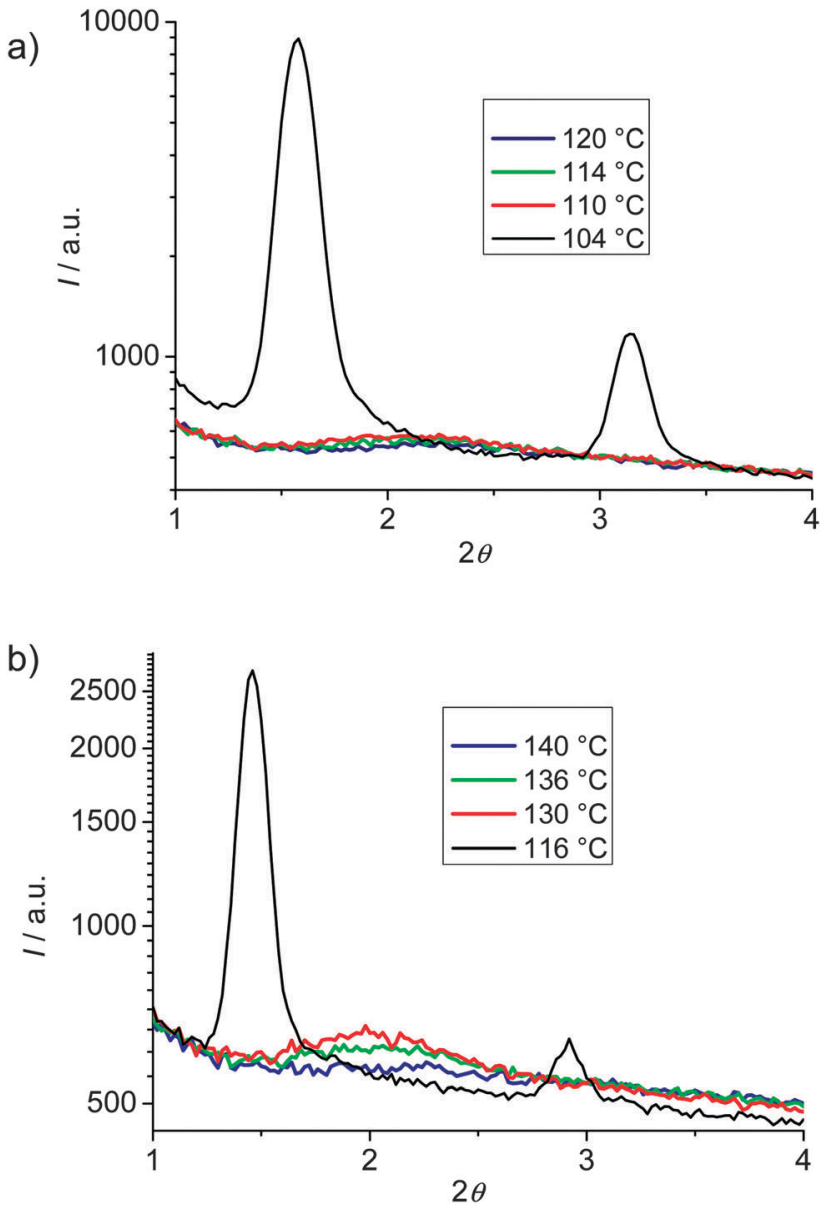

Fig. 4 Small angle XRD patterns of compounds (a) $1^{12} \mathrm{EO}^{3} \mathrm{OH}$ and (b) $1^{12} \mathrm{EO}^{3}(\mathrm{OH})_{2}$ at the indicated temperatures in the smectic phase (black lines) and at different temperatures in the Iso phase in proximity to the $\mathrm{SmA}_{d}-$ Iso transition (colored lines), showing a significant cybotaxis for $1^{12} \mathrm{EO}^{3}(\mathrm{OH})_{2}$ being much weaker for $1^{12} \mathrm{EO}^{3} \mathrm{OH}$.

measured for the related compounds with a single $\mathrm{OH}$ group (see Tables 1 and 2). It appears that for $\mathbf{1}^{\mathbf{1 2}} \mathbf{E O}^{3}(\mathbf{O H})_{2}$ significant cybotactic clusters are already formed in the Iso phase which then fuse to infinite layers at the Iso-Sm phase transition, whereas for $\mathbf{1}^{12} \mathbf{E O} \mathbf{O H}^{3}$ the clusters are much smaller and just at the Iso-Sm transition layer formation starts with much smaller clusters, thus leading to a larger enthalpy for the phase transition.

\subsection{Thermotropic self-assembly of compounds 2 and 3 with two and three alkyl chains in columnar LC phases}

Double and triple chain benzylether 2 and $\mathbf{3}$ are collated in Table 4. Except for compound $3^{\mathbf{1 4}} \mathbf{E} \mathbf{O}^{3} \mathbf{O H}$, other compounds show exclusively hexagonal columnar phases $\left(\mathrm{Col}_{\text {hex }}\right)$. In general 
the stability of LC phases increases with increasing number of $\mathrm{OH}$ groups. The $\mathrm{Col}_{\text {hex }}$-Iso transition enthalpies are in the range between $\Delta H=0.4$ and $1.5 \mathrm{~kJ} \mathrm{~mol}^{-1}$, which is about one order of magnitude smaller than those for the Sm-Iso transitions of compounds $\mathbf{1}$, and there is obviously no dependence of the Col-Iso transition enthalpy on the number of $\mathrm{OH}$ groups.

There is a strong effect of the number of alkyl chains, reducing the mesophase stability with growing chain number (compare compounds $\mathbf{2}^{\mathbf{1 4}}(\mathbf{O H})_{2}$ and $3^{\mathbf{1 4}}(\mathbf{O H})_{2}$ in Table 4). In contrast, the effects of the EO unit between the azobenzene core and the glycerol unit on melting temperatures and mesophase stability are only marginal (compare compounds $3^{n} \mathbf{E O}^{3}(\mathbf{O H})_{2}$ and $\left.3^{n}(\mathbf{O H})_{2}\right)$. The textures of the columnar mesophases, as observed between crossed polarizers, are characterized by 'spherulitic' domains (see Fig. 5a, Fig. S1a and c, ESI $\dagger$ ), combined with regions appearing completely dark, where the optic axis is normal to the LC film (homeotropic regions), see Fig. S1b $(\mathrm{ESI} \dagger)$. These textures indicate an optically uniaxial columnar LC phase The orientation of the $\pi$-conjugated aromatic cores is deduced from the colour of the fans in the micrograph taken with a $\lambda$-retarder plate (Fig. $5 \mathrm{~b}$ and Fig. S1c, ESI $\dagger$ ). The directions of yellow and blue fans with respect to the indicatrix of the retarder confirm the orientation of the high-index axis as radial to the fans. As the columns are tangential and the high-index axis is parallel to the $\pi$-conjugated aromatic cores. This means that in the columns the preferred direction of the intra-molecular $\pi$-conjugation pathway (i.e. the long axis of the azobenzene cores) is on average perpendicular to the column long axis, in line with the proposed mode of self-assembly (see below).

The columnar phases of the double chain glycerol substituted compound $2^{\mathbf{1 4}}(\mathbf{O H})_{2}$, the three chain compound $3^{\mathbf{1 2}}(\mathbf{O H})_{2}$ and the related compound with additional $(\mathrm{EO})_{3}$ unit $3^{\mathbf{1 2}} \mathbf{E O}^{3}(\mathbf{O H})_{2}$ were investigated as representative examples by small-angle X-ray scattering (SAXS), and grazing-incidence small-angle X-ray scattering (GISAXS) on thin surface-aligned films on silicon using a synchrotron source (see Fig. 5d, e and Fig. S2, ESI $\dagger$ ). All columnar phases show three or four small angle reflections with a ratio of their reciprocal spacing $1: 3^{1 / 2}: 2:\left(7^{1 / 2}\right)$ which can be indexed to the 10,11, 20 (and 21) reflections of a hexagonal lattice with $p 6 \mathrm{~mm}$ symmetry (Fig. $5 \mathrm{~d}$ and Fig. S2c, ESI $\dagger$ ). The 2D pattern of an aligned sample of compound $3^{12}(\mathbf{O H})_{2}$ also confirms this phase assignment (Fig. 5e and Fig. S2b, ESI $\dagger$ ). Although SAXS was not carried out on all of the columnar phases, based on textural similarities (Fig. S1, ESI $\dagger$ ), it is very likely that the columnar phases of the other compounds represent the hexagonal columnar phases too. The number of molecules organized in a slice of the columns with a height of $h=0.45 \mathrm{~nm}$ (a typical value for the maximum of the diffuse wide angle scattering) $n_{\text {cell }}$ was estimated using eqn (1) and assuming a density of $\rho=1 \mathrm{~g} \mathrm{~cm}^{-3}\left(N_{\mathrm{A}}=\right.$ Avogadro constant; $M=$ molecular mass, see Table 4). The number decreases from $n_{\text {cell }}=13$ for the two-chain compound $\mathbf{2}^{\mathbf{1 4}}(\mathbf{O H})_{\mathbf{2}}$ to $n_{\text {cell }}=10$ for the three-chain compound $3^{12}(\mathbf{O H})_{2}$. Introduction of the $(\mathrm{EO})_{3}$ unit at constant alkyl chain volume leads to a slight increase of the number of molecules in the column cross section from $n_{\text {cell }}=10$ to 11 for compound $3^{12} \mathbf{E O}^{3}(\mathbf{O H})_{2}$.

$$
n_{\text {cell }}=\left(a^{2} / 2\right) \sqrt{3} h\left(N_{\mathrm{A}} / M\right) \rho
$$

These two- and triple-alkyl chain amphotropic azobenzene derivatives can be either considered as taper shaped molecules, ${ }^{40,41}$ providing a radial organization of the molecules in circular columnar aggregates, thus, directly leading to a packing of the circular columns on a hexagonal lattice (see the model in Fig. 5f), or as polycatenar (three- and tetracatenar, respectively) mesogens, which can organize into ribbons of antiparallel organized molecules, resembling the organization in the smectic phases of the single chain compounds (see the model in Fig. 5h). ${ }^{42,43}$ In the latter case the time and space averaging of the ribbon local orientation would lead to the globally averaged hexagonal lattice. Probably the truth is somewhere in the middle, i.e. the columns have an elliptical shape which retains some ribbon-like organization in the middle and simultaneously the contact between polar groups and aliphatic chains in the periphery is minimized by fusing the aromatic regions to elliptical shells covering the polar regions (Fig. 5g). These elliptical columns are then arranged on a time and space averaged hexagonal lattice. This model is in line with the reconstructed electron density maps (see Fig. 6a and c) where the column centers with high electron

Table 4 Mesophases, transition temperatures $\left(T /{ }^{\circ} \mathrm{C}\right)$ and transitional enthalpy values $\left(\Delta H / \mathrm{kJ}^{\mathrm{mol}}{ }^{-1}\right)$ of the multi-chain compounds 2 and $3^{a}$
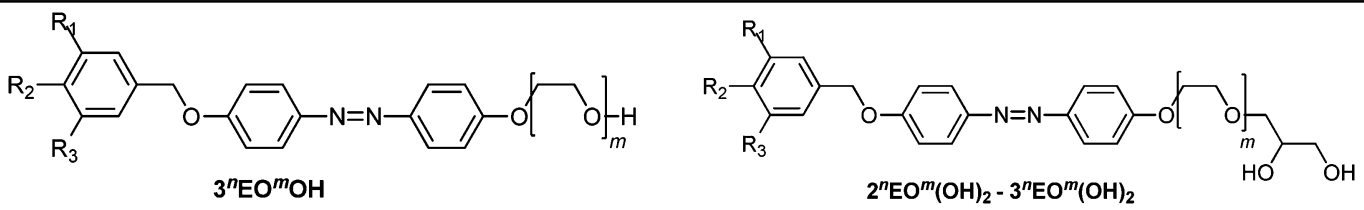

\begin{tabular}{|c|c|c|c|c|c|c|}
\hline Comp & $\mathrm{R}_{1}$ & $\mathrm{R}_{2}, \mathrm{R}_{3}$ & $m$ & Phase transitions & $a / \mathrm{nm}\left(T /{ }^{\circ} \mathrm{C}\right)$ & $n_{\text {cell }}$ \\
\hline $2^{14}(\mathrm{OH})_{2}$ & $\mathrm{H}$ & $\mathrm{OC}_{14} \mathrm{H}_{29}$ & 0 & Cr $115[25.1] \mathrm{Col}_{\text {hex }} 165[1.5]$ Iso & $6.65(140)$ & 13.0 \\
\hline $3^{12}(\mathrm{OH})_{2}$ & $\mathrm{OC}_{12} \mathrm{H}_{25}$ & $\mathrm{OC}_{12} \mathrm{H}_{25}$ & 0 & Cr $59[34.4] \mathrm{Col}_{\text {hex }} 119[0.7]$ Iso & $6.20(90)$ & 9.6 \\
\hline $3^{14}(\mathrm{OH})_{2}$ & $\mathrm{OC}_{14} \mathrm{H}_{29}$ & $\mathrm{OC}_{14} \mathrm{H}_{29}$ & 0 & Cr $64[36.7] \mathrm{Col}_{\text {hex }} 115[0.4]$ Iso & & \\
\hline $3^{12} \mathrm{EO}^{3} \mathrm{OH}$ & $\mathrm{OC}_{12} \mathrm{H}_{25}$ & $\mathrm{OC}_{12} \mathrm{H}_{25}$ & 3 & Cr $74[57.9]\left(\mathrm{Col}_{\text {hex }} 70[0.4]\right)$ Iso & & \\
\hline $3^{14} \mathrm{EO}^{3} \mathrm{OH}$ & $\mathrm{OC}_{14} \mathrm{H}_{29}$ & $\mathrm{OC}_{14} \mathrm{H}_{29}$ & 3 & Cr $78[55.3]$ Iso $^{b}$ & & \\
\hline $3^{12} \mathrm{EO}^{3}(\mathrm{OH})_{2}$ & $\mathrm{OC}_{12} \mathrm{H}_{25}$ & $\mathrm{OC}_{12} \mathrm{H}_{25}$ & 3 & Cr $66[49.6] \mathrm{Col}_{\text {hex }} 115[0.9]$ Iso & $7.17(90)$ & 11.3 \\
\hline $3^{14} \mathrm{EO}^{3}(\mathrm{OH})_{2}$ & $\mathrm{OC}_{14} \mathrm{H}_{29}$ & $\mathrm{OC}_{14} \mathrm{H}_{29}$ & 3 & Cr $71[39.5] \mathrm{Col}_{\text {hex }} 116[0.5]$ Iso & & \\
\hline
\end{tabular}

${ }^{a}$ Abbreviations: $\mathrm{Col}_{\text {hex }}=$ hexagonal columnar phase with $p 6 \mathrm{~mm}$ symmetry; for conditions and other explanations see Table $1 .{ }^{b}$ No LC phase was observed upon cooling before crystallization at $T=62{ }^{\circ} \mathrm{C}$. 

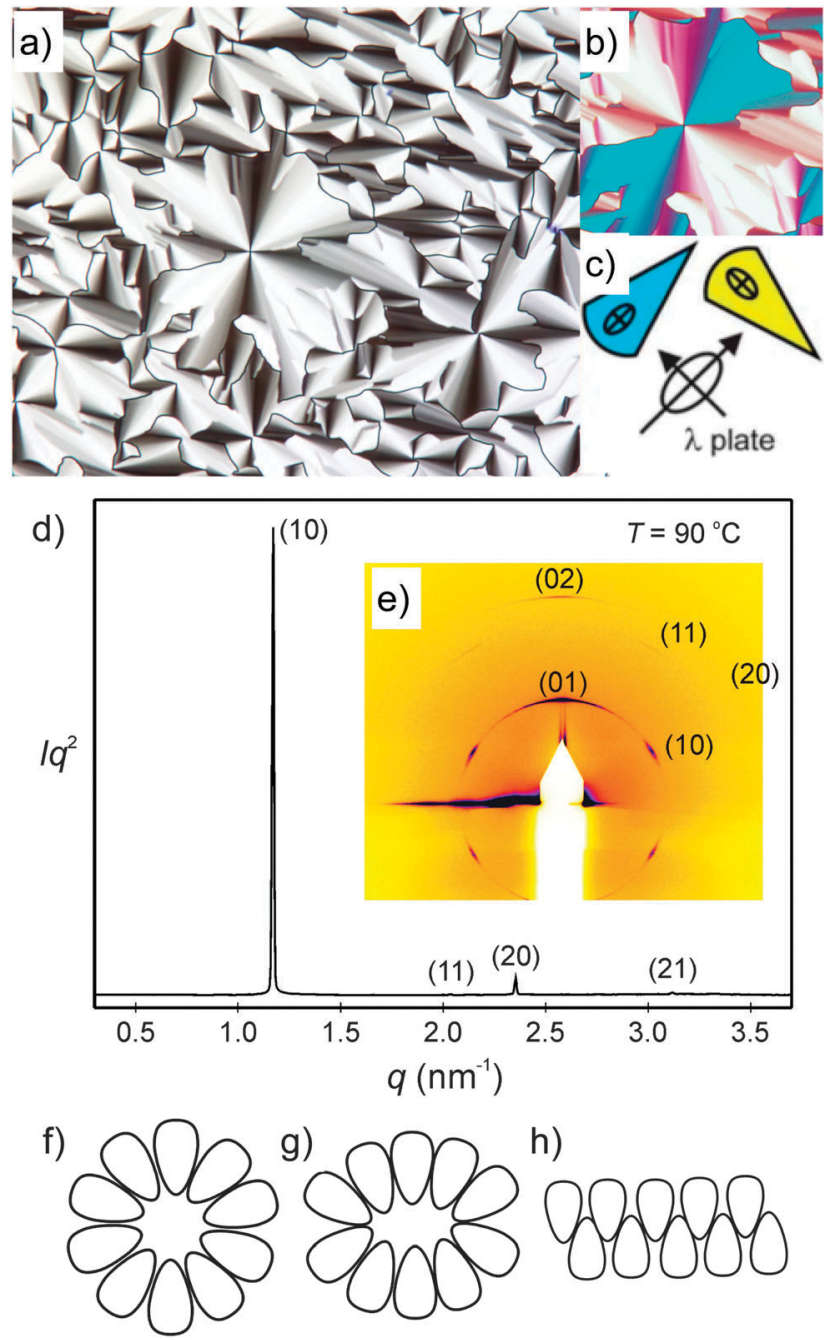

Fig. 5 Investigation of compound $3^{12}(\mathrm{OH})_{2}$ (a) texture of the columnar phase at $T=90{ }^{\circ} \mathrm{C}$ as observed between crossed polarizers; (b) shows a section of the texture with an additional $\lambda$-retarder plate and the orientation of the indicatrix of the $\lambda$-plate is shown in (c); (d) powder X-ray diffraction pattern at $T=90^{\circ} \mathrm{C}$ and (e) GISAXS pattern of a surface-aligned sample at $T=90{ }^{\circ} \mathrm{C}$; ( $\mathrm{f}-\mathrm{h}$ ) models showing the organization of the amphiphilic molecules, (f) in circular columns, (g) in elliptical columns and $(h)$ in ribbons; for more details, see Tables S4-S7 and Fig. S2 (ESI $\dagger$ ).

density (purple) are surrounded by medium electron density shells (blue/green/yellow). The medium electron density shells might result from the rotational disorder of the elliptical columns leading to a space and time averaging of the high electron density polar cores and the low electron density alkyl chains in the continuum around the columns. In the column cores only the aromatic/polar cores of the elliptical columns overlap on the space and time average, leading to high electron density. Independent of the precise shape of the columns the rigid aromatics, the polar groups (polyether and glycerol unit) and the non-polar alky chains segregate into distinct domains. The polar units form the column centers, which are surrounded by the azobenzene cores and assembled on a hexagonal lattice within the lipophilic continuum mainly formed by the alkyl chains. The three alkyl chains of $3^{\mathbf{1 2}}(\mathbf{O H})_{2}$ provide a stronger interface curvature leading to a $30 \%$ decrease of the number of molecules
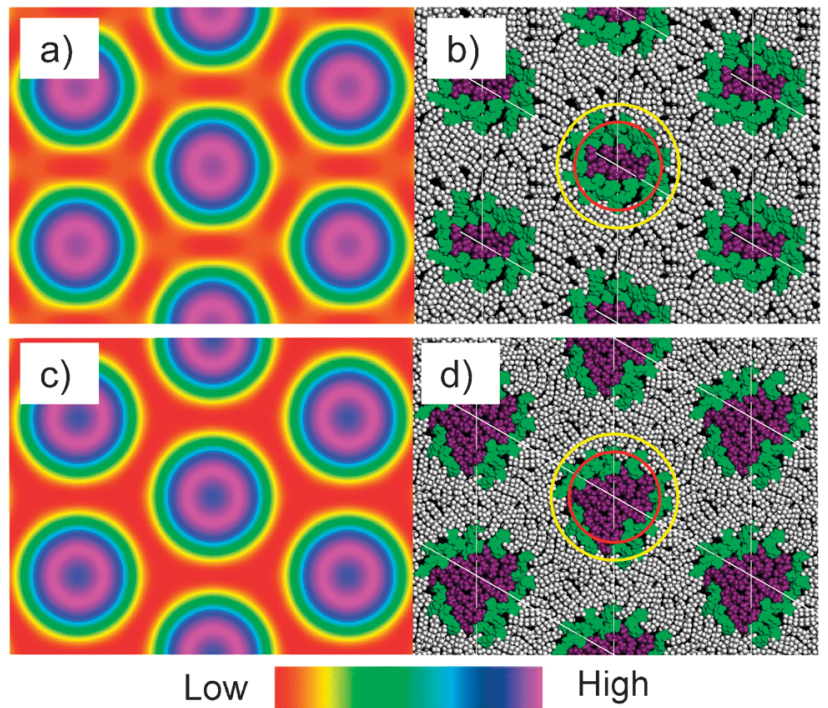

Fig. 6 Electron density maps of the $\mathrm{Col}_{\text {nex }}$ phases of (a) compound $3^{12}(\mathrm{OH})_{2}$ and (c) compound $3^{12} \mathrm{EO}^{4}(\mathrm{OH})_{2}$ as reconstructed from the synchrotron powder diffraction patterns (color code: purple/blue = high, green/yellow = medium and red = low electron density; for details of the reconstruction, see the ESI + ); (b) snapshot of the structure of the Colnex phase of $3^{12}(\mathrm{OH})_{2}$ and (d) of $3^{12} \mathrm{EO}^{3}(\mathrm{OH})_{2}$ after MD annealing (polar groups are colored purple and the aromatic cores green, alkyl chains gray); red and yellow circles represent the boundaries between high and medium and medium and low electron density regions in the electron density maps, respectively.

organized in the cross section of the columns $\left(n_{\text {cell }}=10\right)$ compared to the double chain compound $\mathbf{2}^{\mathbf{1 4}}(\mathbf{O H})_{\mathbf{2}}\left(n_{\text {cell }}=13\right)$. Enlargement of the polar group by the $(\mathrm{EO})_{3}$ chain increases the polar volume and this reduces the interface curvature, thus leading to a slight increase in the number of molecules organized in the cross section of the columns $\left(n_{\text {cell }}=11\right.$ for $\left.3^{12} \mathbf{E} \mathbf{O}^{3}(\mathbf{O H})_{2}\right)$.

In Fig. 6 the reconstructed electron density maps of the $\mathrm{Col}_{\text {hex }}$ phases of compounds $3^{12}(\mathbf{O H})_{2}$ and $3^{12} \mathbf{E O}^{3}(\mathbf{O H})_{2}$ (left) are compared with the molecular dynamics (MD) annealed models of the columnar phases (right). The MD annealed model of the columnar phase of $3^{\mathbf{1 2}} \mathbf{E} \mathbf{O}^{3}(\mathbf{O H})_{2}$ (Fig. 6d) indicates that the polar chains form the majority of the column cores and the azobenzenes form a kind of shell separating the polar core from the aliphatic continuum, in which the alkyl chains are completely disordered and partly interdigitated. The formation of this kind of aromatic shell is favored by the possibility of hydrogen bonding of the $\mathrm{OH}$ groups to the azo groups, to the electron rich aromatic $\pi$-systems and to the ether oxygens at the aromatics. The MD annealed model of the columnar phase of $3^{\mathbf{1 2}}(\mathbf{O H})_{2}$ (Fig. 6b) without EO units shows better defined shells of the aromatic cores with a larger degree of parallel alignment of the cores around the smaller core regions involving the polar groups (structure corresponding to the model in Fig. 5g).

\subsection{Effects of solvents and lyotropic self-assembly}

The effect of protic solvents on the phase behavior of $\mathbf{1}^{12} \mathbf{E} \mathbf{O}^{3} \mathbf{O H}$ as a representative example was investigated by POM and XRD. By adding ethylene glycol, the SmC phase of this compound is first stabilized, but already at $n_{\mathrm{EO}} \sim 1\left(n_{\mathrm{EO}}=n(\mathrm{EO}) / n\left(\mathbf{1}^{\mathbf{1 2}} \mathbf{E O}^{3} \mathbf{O H}\right)\right)$ 
the stability of the SmC phase decreases and a SmA phase occurs (Fig. 7). With further increase in solvent concentration, the SmCSmA transition temperature decreases whereas the SmA phase stability increases. The SmC phase exhibits a typical schlieren texture as observed for the dry compound and the SmA phase shows oily streaks and homeotropic areas as characteristic of lyotropic SmA phases (Fig. 8). At $n_{\mathrm{EO}} \sim 4$ the maximum of the phase stability is reached and with a further increase in solvent concentration the transition temperatures slightly decrease up to $n_{\mathrm{EO}} \sim 11$ which represents the maximum uptake of the solvent (Fig. 7). After reaching this concentration the system remained heterogeneous with excess solvent coexisting with the lyotropic LC system.

The system was in addition investigated by XRD for the concentrations $n_{\mathrm{EO}} \sim 1(\sim 10 \mathrm{wt} \% \mathrm{EO}), n_{\mathrm{EO}} \sim 3(\sim 30 \mathrm{wt} \% \mathrm{EO})$ and $n_{\mathrm{EO}} \sim 10(\sim 50 \mathrm{wt} \% \mathrm{EO})$. The XRD patterns showed the typical diffraction patterns of smectic phases. There is a significant increase of the $d$-spacings with increasing solvent content, in line with a swelling of the polar layers by the added solvent molecules. Remarkably, the layer shrinkage at the SmA-SmC transition and in the temperature range of the SmC phase increases with increasing solvent content. In contrast, the layer spacing $d$ remains nearly constant in the SmC phase region of the solvent-free sample (see Fig. 9). This could have different reasons, for example, the solvation of the head groups could change, i.e. the number of molecules separating the head groups laterally increases and simultaneously the number of solvent molecules arranged between the layers decreases with decreasing temperature. This could further lead to a stronger intercalation of the alkyl chains and an increase of the uniform $(\mathrm{SmC})$ or average tilt $(\mathrm{SmA})$ of the aromatic at lower temperature. The combined contribution of these effects is thought to lead to the observed effect.

A similar behaviour to that with EO was also observed using water and formamide, which were investigated by contact preparation. For this purpose the amphiphile and the solvent were placed side-by-side between two glass plates and the phases developing in the contact region due to the developing concentration gradient were observed under a polarizing microscope. In all cases a SmA

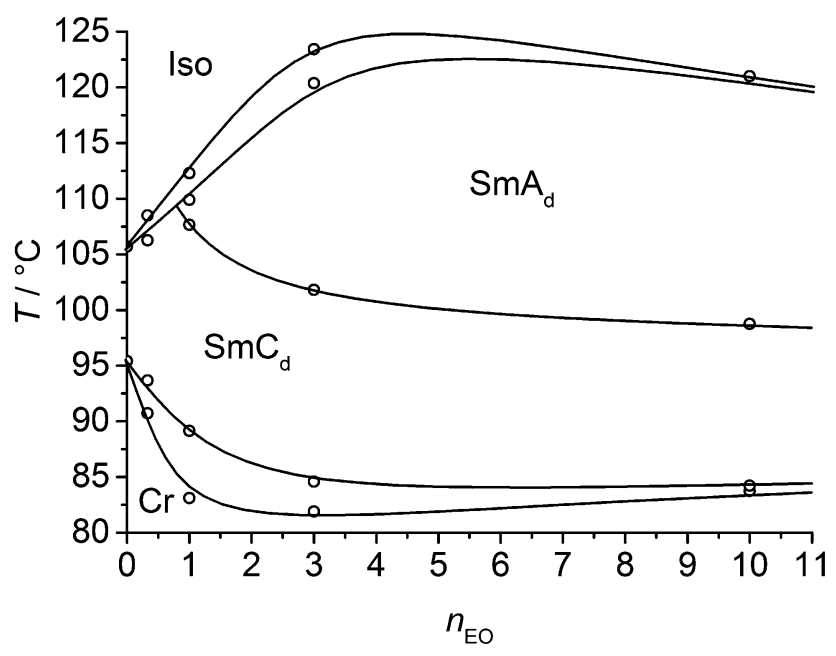

Fig. 7 Phase diagram of the system $1^{12} \mathrm{EO}^{3} \mathrm{OH} /$ ethylene glycol (EO).

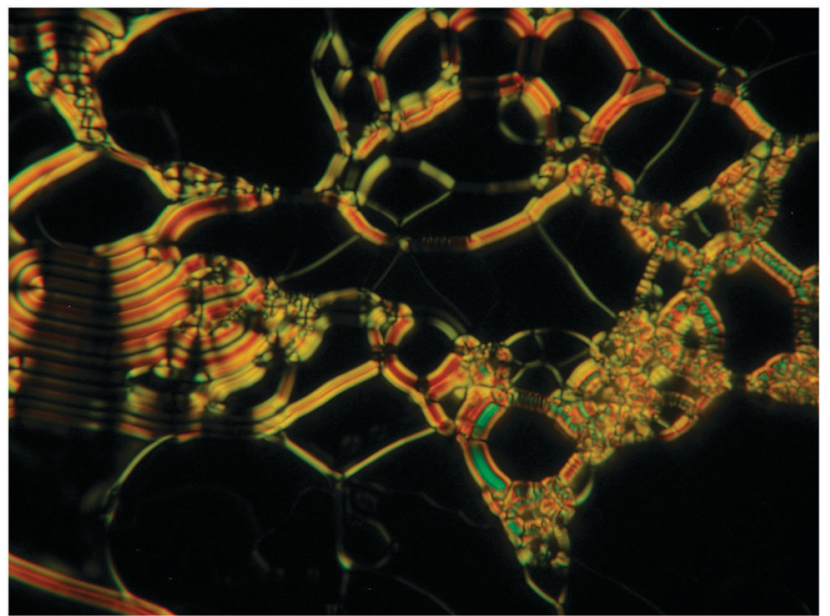

Fig. 8 Texture of the solvent induced lyotropic SmA phase of $1^{12} \mathrm{EO}$ at $T=105^{\circ} \mathrm{C}$ in a mixture with ethylene glycol (EO) at $n_{\mathrm{EO}}=10$.

phase was induced and an SmC-SmA-Iso phase sequence was found for the solvent enriched samples. For formamide a bit higher transition temperatures were observed for the solvent saturated sample ( $\mathrm{Cr} 7{ }^{\circ} \mathrm{C} \mathrm{SmC} 90{ }^{\circ} \mathrm{C}$ SmA $135{ }^{\circ} \mathrm{C}$ Iso), compared with EO, whereas for water the observed transition temperatures are lower (Cr $78{ }^{\circ} \mathrm{C} \mathrm{SmC} 80{ }^{\circ} \mathrm{C} \mathrm{SmA} 97{ }^{\circ} \mathrm{C}$ Iso for the water saturated sample). This is a bit surprising, as usually water provides the most efficient polar protic solvent, leading to the highest lyotropic phase stabilities. ${ }^{5}$

Additional compounds were investigated using formamide as the protic solvent. In the case of $\mathbf{1}^{\mathbf{1 2}} \mathbf{E O}^{\mathbf{3}}(\mathbf{O H})_{2}$ with an additional glycerol group there is an even stronger stabilization of the SmA phase, reaching about $180{ }^{\circ} \mathrm{C}$ for the formamide saturated sample. This formamide saturated sample crystallizes at $68{ }^{\circ} \mathrm{C}$ without formation of a SmC phase, i.e. there is a stronger destabilization of the tilted SmC phase. Compound $3^{12}(\mathbf{O H})_{2}$ with a glycerol unit but without the EO segments

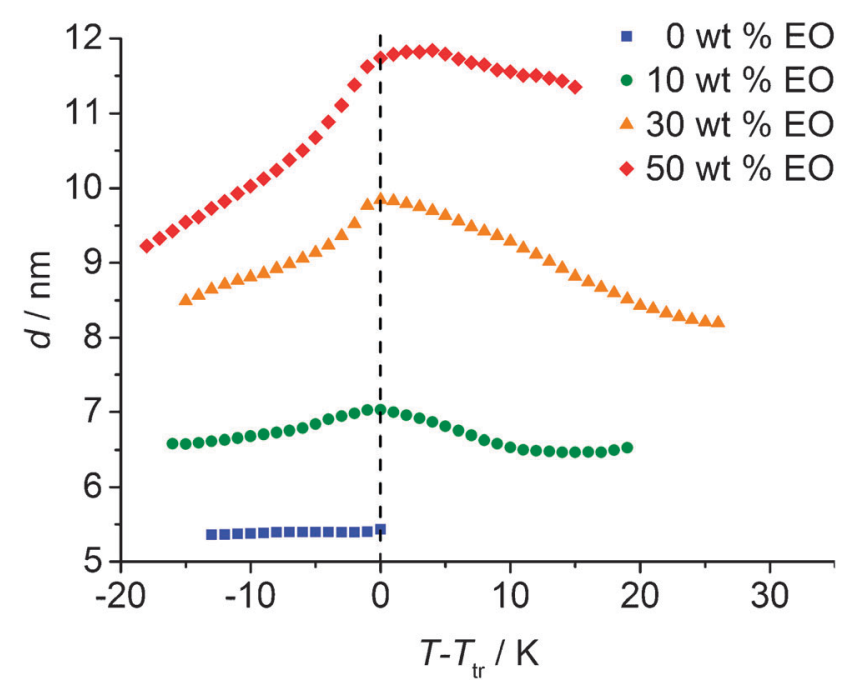

Fig. 9 Temperature dependence of the layer spacing depending on the $\mathrm{EO}$ content of the system $\mathbf{1}^{12} \mathrm{EO}^{3} \mathrm{OH} /$ ethylene glycol (EO). 
behaves similar, the SmA phase being stabilized to $>200{ }^{\circ} \mathrm{C}$, but the formamide saturated sample rapidly crystallizes already at $123{ }^{\circ} \mathrm{C}$ before the transition of the SmA to the SmC phase can take place.

The lyotropic behavior of the three chain compounds is very different and for these compounds a strong dependence of the phase sequence on the type of polar group is observed. Compounds $3^{12} \mathbf{E O}^{3}(\mathrm{OH})_{2}, 3^{12} \mathbf{E O}^{3} \mathrm{OH}$ and $3^{12}(\mathrm{OH})_{2}$ having identical alkyl chain lengths but different types of polar groups were investigated as representative examples using formamide as the polar protic solvent (contact preparations). The columnar phases of $3^{12}(\mathbf{O H})_{2}$ and $3^{12} \mathbf{E O}^{3} \mathbf{O H}$, having either the glycerol group or the triethyleneglycol chain, were completely removed in the contact region and only crystallization was observed at $T=50{ }^{\circ} \mathrm{C}$ for both compounds. In contrast, for compound $3^{12} \mathbf{E O}^{3}(\mathbf{O H})_{2}$, combining the EO chain with the glycerol group, a dramatic stabilization of the $\mathrm{Col}_{\text {hex }}$ phase was observed (see Fig. 10), it is retained up to the boiling point of this solvent at $210{ }^{\circ} \mathrm{C}$. It appears that the molecular organization in columns with a polar interior restricts the effect of the solvent on the self assembly. In the case of relatively small polar groups the volume added by the solvent molecules to the polar groups distorts the formation of columnar aggregates, but it appears to be too small for a transition to a lamellar organization; therefore order is lost and an isotropic liquid is formed. For compound $3^{12} \mathbf{E O}^{3}(\mathbf{O H})_{2}$ with the largest polar group, involving a strong hydrogen bond donor group (the glycerol units) and having several additional hydrogen bonding acceptor sites along the EO chains, a small number of formamide molecules might be sufficient to dramatically increase the number of attractive hydrogen bonds, thus stabilizing the columnar aggregates without requiring too much additional space, and thus retaining the interface curvature. Moreover, as shown in Fig. 6d, the major part of the columns is formed by the polar groups, i.e. polarapolar segregation is dominating the behaviour of $3^{12} \mathbf{E O}^{3}(\mathbf{O H})_{2}$. The azobenzenes being strongly tilted and some of them organized

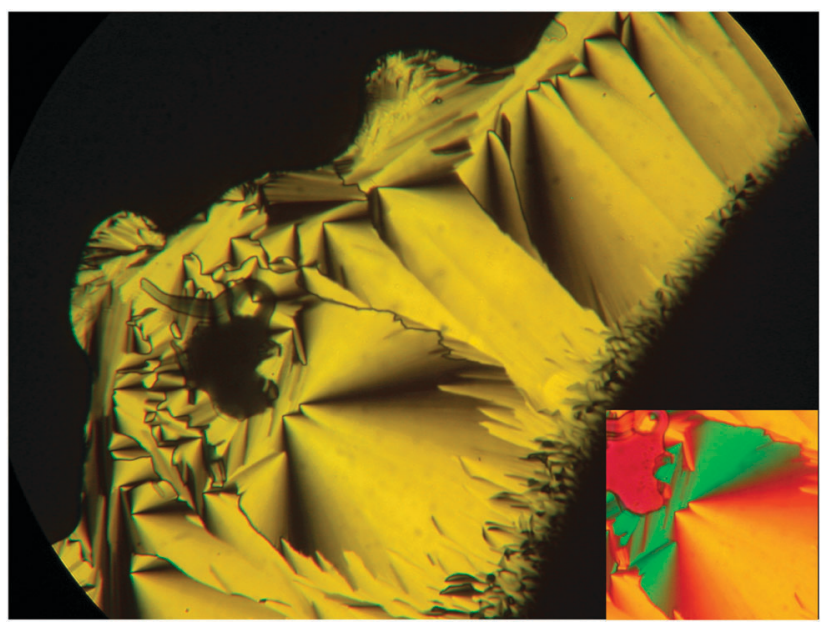

Fig. 10 Texture of the solvent stabilized lyotropic Colnex phase of $3^{12} \mathrm{EO}^{3}(\mathrm{OH})_{2}$ (right) at $T=170{ }^{\circ} \mathrm{C}$ in the contact region with formamide (left) as observed upon cooling, the inset shows the texture with the additional $\lambda$-plate. nearly parallel to the column surface form a relatively thin shell. This might reduce the sensitivity to steric distortions of columnar self assembly and could lead to the very special behavior of this compound.

Investigation of aqueous systems was more difficult due to easy water evaporation, but in principle the behaviour can be considered as similar to formamide. So the $\mathrm{Col}_{\text {hex }}$ phase of $3^{\mathbf{1 2}} \mathbf{E O}^{3}(\mathbf{O H})_{2}$ is retained in the contact region in the whole temperature region available for investigation, whereas for $3^{12} \mathbf{E O}^{3} \mathbf{O H}$ and $3^{12}(\mathbf{O H})_{2}$ the columnar phases are removed for the water saturated samples. It appears that for $3^{\mathbf{1 2}}(\mathbf{O H})_{2}$ an additional lamellar phase is induced in the water saturated sample with a clearing temperature of $71{ }^{\circ} \mathrm{C}$, but this is not completely certain due to the above mentioned difficulties in handling these amphiphile water systems.

\subsection{Photoisomerization behavior}

All compounds 1-3 exhibit the expected reversible photoresponsive behavior (see Fig. 11). All azobenzene derivatives in the $E$-form show a strongly absorbing band in the UV region $(\sim 360 \mathrm{~nm})$ which is attributed to the $\pi-\pi^{*}$ transition, and a weakly absorbing band in the visible region $(\sim 450 \mathrm{~nm})$ due to the $\mathrm{n}-\pi^{*}$ transition. The $E$-form is generally more stable than the $Z$-form, but each isomer can be converted into the other by light-irradiation caused a decrease of the absorption at around $355 \mathrm{~nm}$ and an increase of the absorption at around $450 \mathrm{~nm}$. For example, dark incubation of a dichloromethane solution $\left(1 \times 10^{-5} \mathbf{M}\right)$ of $\mathbf{1}^{\mathbf{1 2}} \mathbf{E O}^{3} \mathbf{O H}$ have a maximum absorbance at $358 \mathrm{~nm}$ corresponding to the $E$-azobenzene chromophore $\left(\pi-\pi^{*}\right.$ transition). Upon irradiation of this solution with $365 \mathrm{~nm}$ light resulted in photoisomerization from the $E$-azobenzene to the $Z$-azobenzene chromophore, as evidenced by a decrease in absorbance at $358 \mathrm{~nm}$ and an increase in absorbance at $450 \mathrm{~nm}$ (n- $\pi^{*}$ transition). Also the absorbance at $313 \mathrm{~nm}\left(\pi-\pi^{*}\right.$ transition) increased. The $E-Z$ transition was complete in $35 \mathrm{~s}$ (see Fig. 11a). Under visible light, the reverse $E-Z$ transition process was achieved within 6 min (see Fig. 11b).

The effect of $E$-to- $Z$ photoisomerization caused by the UV irradiation on the thermotropic LC phases was investigated using compound $\mathbf{1}^{\mathbf{1 2}} \mathbf{E} \mathbf{O}^{3} \mathbf{O H}$ as an example. The sample was placed between two thin quartz glass plates to form a thin film and placed on a Linkam hot stage that can control the sample temperature within $0.1{ }^{\circ} \mathrm{C}$. The sample was cooled from the isotropic liquid state to $98{ }^{\circ} \mathrm{C}$ in the range of the $\mathrm{SmC}_{\mathrm{d}}$ phase (see Fig. S6a, ESI $\dagger$ ). After annealing for 5 minutes the sample was exposed to UV irradiation at $365 \mathrm{~nm}\left(5 \mathrm{~mW} \mathrm{~cm}^{-2}\right)$ for $60 \mathrm{~s}$. After $\sim 20 \mathrm{~s}$ exposure time the schlieren texture of the $\mathrm{SmC}_{\mathrm{d}}$ phase has changed to a plain fan texture separated by homeotropic areas, indicating that the $\mathrm{SmC}_{\mathrm{d}}$ phase is replaced by a SmA phase (most probably $\mathrm{SmA}_{d}$; see Fig. S6b and c, ESI $\dagger$ ). After thermal annealing at the same temperature of $98{ }^{\circ} \mathrm{C}$ without irradiation a slow change in the texture back to the $\mathrm{SmC}_{\mathrm{d}}$ phase took place, indicating a thermal $Z-E$ isomerization (see Fig. S6d and e, ESI $\dagger$ ). So the $E-Z$ photoisomerization allows a reversible switching between $\mathrm{SmC}$ and $\mathrm{SmA}$ at a fixed temperature. This is due to a change in the phase transition temperatures. 
a)
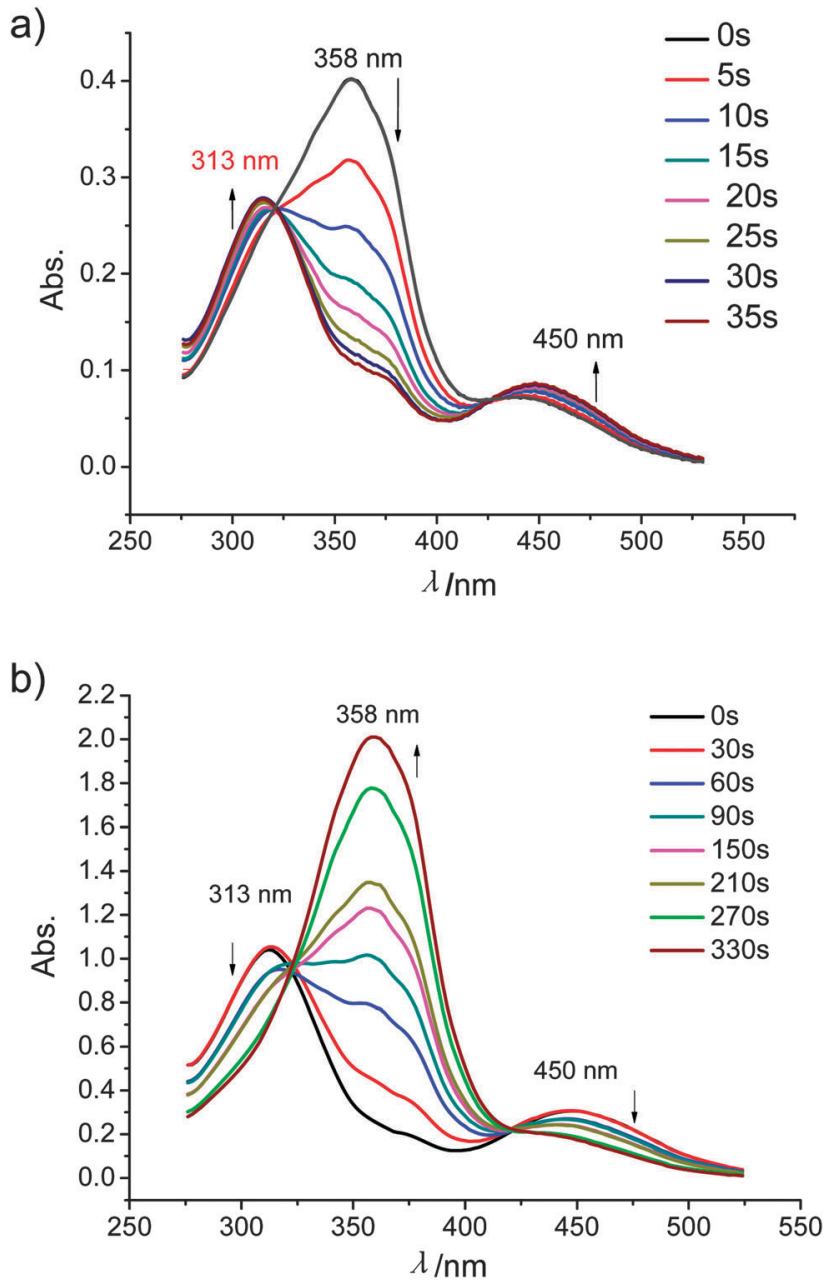

Fig. $11 \mathrm{UV}$ spectra of $\mathbf{1}^{12} \mathrm{EO}^{3} \mathrm{OH}$ in $\mathrm{CH}_{2} \mathrm{Cl}_{2}$ solution $\left(c=10^{-5} \mathrm{~mol} \mathrm{~L}^{-1}\right.$ ), changing with time: (a) from $E$ - to $Z$-azobenzene under irradiation with $365 \mathrm{~nm}$ light; (b) from $Z$ - to $E$-azobenzene under irradiation with visible light; for additional examples, see Fig. S3 and S4 (ESI†).

For example, a sample exposed for $30 \mathrm{~s}$ has the phase sequence $\mathrm{Cr}$ $86{ }^{\circ} \mathrm{C}$ SmC $94{ }^{\circ} \mathrm{C} \mathrm{SmA} 99{ }^{\circ} \mathrm{C}$ Iso. This means that photoisomerization induces a SmA phase and reduces the Sm-Iso transition temperature (compare with Table 1). It appears that the isomerization process in the LC state is significantly slower than in the isotropic solution. Nevertheless, in the LC state the photoinduced $E$-to- $Z$ transitions is still sufficiently fast and requires only a few seconds to induce a SmA phase, whereas the thermal relaxation to the SmC phases is much slower, requiring about 1 hour at the used temperature. Such photoisomerizations could be useful for light sensitive displays or for data storage applications.

\section{Conclusion}

A series of amphotropic azobenzene derivatives with a different number of alkyl chains and a distinct structure of the polar groups was synthesized and investigated with respect to thermotropic and lyotropic self-assembly in LC phases. Most compounds with only one $n$-alkyl chain form fluid tilted smectic phases with a double layer structure $\left(\mathrm{SmC}_{\mathrm{d}}\right)$. Compounds with a single hydroxyl group form exclusively the $\mathrm{SmC}_{\mathrm{d}}$ phase whereas a $\mathrm{SmC}_{\mathrm{d}} / \mathrm{SmA}_{\mathrm{d}}$ dimorphism was observed for most of the related diols. SmA phases were induced and stabilized by addition of protic solvents. This means that increased head group size favors SmA phases, but nevertheless broad regions of lyotropic SmC phases were retained. Such SmC phases are rarely observed in lyotropic LC phases and these materials are of interest as lyotropic ferroelectrics after introduction of chirality. ${ }^{10 b}$ The SmC-SmA transition can be considered as mainly resulting from the randomization of the tilt by the lateral separation of the molecules by the solvent molecules located around the polar groups. The increased effective polar group volume also reduces the tilt correlation between the layers.

Compounds with two or three alkyl chains form exclusively $\mathrm{Col}_{\text {hex }}$ phases and there is a strong effect of protic solvents, stabilizing $\mathrm{Col}_{\text {hex }}$ phases of compounds combining EO chains with glycerol units and removing columnar phases for compounds having only one of them, either EO chains or glycerol units. All amphiphiles show photoresponsive behavior, which makes these compounds interesting for potential applications as photoresponsive amphiphiles and LCs.

\section{Acknowledgements}

This work was supported by NSFC (No. 21364017, 21274119, 21374086), YNSF (2013FA007), YED (ZD2015001), DFG FOR 1145 (Ts 39/21-2). MP acknowledges support from the Cluster of Excellence "Nanostructured Materials" of the government of Saxony-Anhalt and JRB acknowledges financial support from the "Landesgraduiertenförderung" of the state Baden-Württemberg.

\section{References}

1 J. W. Steed and J. L. Atwood, Encyclopedia of Supramolecular Chemistry, Marcel Dekker, New York, 2004; J. M. Lehn, Supramolecular Chemistry, VCH, Weinheim, 1995.

2 (a) C. Tschierske, Angew. Chem., Int. Ed., 2013, 52, 8828-8878; (b) B. Donnio and D. Guillon, Adv. Polym. Sci., 2006, 201, 145-155; (c) T. Kato, N. Mizoshita and K. Kishimoto, Angew. Chem., 2006, 118, 44-74; (d) M. Lee, B.-K. Cho and W.-C. Zin, Chem. Rev., 2001, 101, 3869-3892; (e) I. M. Saez and J. W. Goodby, J. Mater. Chem., 2005, 15, 26-40; $(f)$ G. Ungar and X. Zeng, Soft Matter, 2005, 1, 95-106.

3 H. Ringsdorf, B. Schlarb and J. Venzmer, Angew. Chem., 1988, 100, 117-162.

4 (a) R. Duran and P. Gramain, Makromol. Chem., 1987, 188, 2001-2009; (b) R. Duran, D. Guillon, P. Gramain and A. Skoulios, J. Phys., 1988, 49, 1455-1466; (c) H. R. Allcock and C. Kim, Macromolecules, 1989, 22, 2596-2602; (d) V. Percec and C.-S. Hsu, Polym. Bull., 1990, 23, 463-470; (e) V. Percec, D. Tomazos, J. Heck, H. Blackwell and G. Ungar, J. Chem. Soc., Perkin Trans. 2, 1994, 31-44.

5 (a) C. Tschierske, Prog. Polym. Sci., 1996, 21, 775-852; (b) M. Kölbel, T. Beyersdorff, C. Tschierske, S. Diele and J. Kain, Chem. - Eur. J., 2000, 6, 3821-3837; (c) C. Tschierske, Curr. Opin. Colloid Interface Sci., 2002, 7, 355-370. 
6 (a) B. Neumann, C. Sauer, S. Diele and C. Tschierske, J. Mater. Chem., 1996, 6, 1087-1098; (b) C. Tschierske, J. A. Schröter, N. Lindner, C. Sauer, S. Diele, R. Festag, M. Wittenberg and J.-H. Wendorff, SPIE, 1998, 3319, 8-13; (c) C. Sauer, S. Diele and C. Tschierske, Liq. Cryst., 1997, 23, 911-917; (d) C. Sauer, S. Diele, N. Lindner and C. Tschierske, Liq. Cryst., 1998, 25, 109-116.

7 N. Lindner, M. Kölbel, C. Sauer, S. Diele, J. Jokiranta and C. Tschierske, J. Phys. Chem. B, 1998, 102, 5261-5273.

8 A. Bubnov, M. Kašpar, V. Hamplová, U. Dawin and F. Giesselmann, J. Org. Chem., 2013, 9, 425-436.

9 N. Pietschmann, A. Lunow, G. Brezesinski, C. Tschierske, F. Kuschel and H. Zaschke, Colloid Polym. Sci., 1991, 269, 636-639.

10 (a) J. R. Bruckner, D. Krueerke, J. H. Porada, S. Jagiella, D. Blunk and F. Giesselmann, J. Mater. Chem., 2012, 22, 18198-18203; (b) J. R. Bruckner, J. H. Porada, C. F. Dietrich, I. Dierking and F. Giesselmann, Angew. Chem., Int. Ed., 2013, 52, 8934-8937.

11 (a) C. Tschierske, A. Lunow, D. Joachimi, F. Hentrich, D. Girdziunaite, H. Zaschke, A. Mädicke, G. Brezesinski and F. Kuschel, Liq. Cryst., 1991, 9, 821-829; (b) H. Müller and C. Tschierske, J. Chem. Soc., Chem. Commun., 1995, 645-646.

12 (a) D. Joachimi, C. Tschierske, A. Öhlmann and W. Rettig, J. Mater. Chem., 1994, 4, 1021-1027; (b) D. Joachimi, A. Öhlmann, W. Rettig and C. Tschierske, J. Chem. Soc., Perkin Trans. 2, 1994, 2011-2019.

13 T. Kato, Angew. Chem., Int. Ed., 2010, 49, 7847-7848.

14 (a) T. Ube and T. Ikeda, Angew. Chem., Int. Ed., 2014, 53, 10290-10299; (b) H. M. Dhammika Bandarab and S. C. Burdette, Chem. Soc. Rev., 2012, 41, 1809-1825.

15 (a) T. Ikeda, J. Mamiya and Y. Yu, Angew. Chem., Int. Ed., 2007, 46, 506-528; (b) E. V. Fleischmann and R. Zentel, Angew. Chem., Int. Ed., 2013, 52, 8810-8827 (Angew. Chem., 2013, 125, 8972-8991).

16 (a) Y. Yu, M. Nakano and T. Ikeda, Nature, 2003, 425, 145; (b) Y. Yu, M. Nakano, A. Shishido, T. Shishido and T. Ikeda, Chem. Mater., 2004, 16, 1637-1643; (c) M. Kondo, Y. Yu and T. Ikeda, Angew. Chem., Int. Ed., 2006, 45, 1378-1382; (d) Y. Yu, T. Maeda, J. Mamiya and T. Ikeda, Angew. Chem., Int. Ed., 2007, 46, 881-883; (e) Y. Zhang, J. Xu, F. Cheng, R. Yin, C.-C. Yen and Y. Yu, J. Mater. Chem., 2010, 20, 7123-7130.

17 (a) R. F. Tabor, D. D. Tan, S. S. Han, S. A. Young, Z. L. E. Seeger, M. J. Pottage, C. J. Garvey and B. L. Wilkinson, Chem. Eur. J., 2014, 20, 13881-13884.

18 X. M. Liu, B. Yang, Y. L. Wang and J. W. Wang, Chem. Mater., 2005, 17, 2792-2799.

19 (a) S. K. M. Nalluri and B. Jan Ravoo, Angew. Chem., Int. Ed., 2010, 49, 5371-5374 (Angew. Chem., 2010, 122, 5499-5502); (b) F. P. Hubbard, G. Santonicola, E. W. Kaler and N. L. Abbott, Langmuir, 2005, 21, 6131-6136.

20 C. T. Jr. Lee, K. A. Smith and T. A. Hatton, Macromolecules, 2004, 37, 5397-5405.

21 J. Eastoe and A. Vesperinas, Soft Matter, 2005, 1, 338-347.

22 (a) N. Drillaud, E. Banaszak-Leonard, I. Pezron and C. Len, J. Org. Chem., 2012, 77, 9553-9561; (b) R. Bianchini,
G. Catelani, R. Cecconi, F. D’Andrea, E. Frino, J. Isaad and M. Rolla, Carbohydr. Res., 2008, 343, 2067-2074.

23 (a) J. M. Kuiper and J. B. F. N. Engberts, Langmuir, 2004, 20, 1152-1160; (b) Y. Okuia and M. HanRational, Chem. Commun., 2012, 48, 11763-11765; (c) E. Chevallier, C. Monteux, F. Lequeux and C. Tribet, Langmuir, 2012, 28, 2308-2312.

24 (a) T. G. Shang, K. A. Smith and T. A. Hatton, Adv. Mater., 2014, 26, 1918-1922; (b) S. Aya, H. Obara, D. Pociecha, F. Araoka, K. Okano, K. Ishikawa, E. Gorecka, T. Yamashita and H. Takezoe, Adv. Mater., 2014, 26, 1918-1922; (c) M. Badis, M. H. Guermouche, J.-P. Bayle, M. Rogalski and E. Rogalska, Langmuir, 2004, 20, 7991-7997.

25 C. Kördel, C. S. Popeney and R. Haag, Chem. Commun., 2011, 47, 6584-6586.

26 Y. Y. Lin, Y. Qiao, C. Gao, P. F. Tang, Y. Liu, Z. B. Li, Y. Yan and J. B. Huang, Chem. Mater., 2010, 22, 6711-6717.

27 (a) D. G. Whitten, L. H. Chen, H. C. Geiger, J. Perlstein and X. D. Song, J. Phys. Chem. B, 1998, 102, 10098-10111; (b) E. H. G. Backus, J. M. Kuiper, J. B. F. N. Engberts, B. Poolman and M. Bonn, J. Phys. Chem. B, 2011, 115, 2294-2302.

28 (a) D.-Y. Kim, S.-A. Lee, Y.-J. Choi, S.-H. Hwang, S.-W. Kuo, C. Nah, M.-H. Lee and K.-U. Jeong, Chem. - Eur. J., 2014, 20, 5689-5695; (b) Z. H. Shi, D. Z. Chen, H. J. Lu, B. Wu, J. Ma, R. S. Cheng, J. L. Fang and X. F. Chen, Soft Matter, 2012, 8, 6174-6184.

29 N. Laurent, N. Lafont, F. Dumoulin, P. Boullanger, G. Mackenzie, P. H. J. Kouwer and J. W. Goodby, J. Am. Chem. Soc., 2003, 125, 15499-15506.

30 B. Soberats, E. Uchida, M. Yoshio, J. Kagimoto, H. Ohno and T. Kato, J. Am. Chem. Soc., 2014, 136, 9552-9555.

31 F. A. Khan, K. Parasuraman and B. Donnio, Tetrahedron, 2010, 66, 8745-8755.

32 (a) R. Willstätter and M. Benz, Chem. Ber., 1906, 339, 3492-3503; (b) W. H. Wei, T. Tomohiro, M. Kodaka and H. Okuno, J. Org. Chem., 2000, 65, 8979-8987.

33 V. Van Rheenen, D. Y. Cha and W. M. Hartley, Org. Synth., 1978, 58, 43-51.

34 T. P. Rieker, N. A. Clark, G. S. Smith, D. S. Parmar, E. B. Sirota and C. R. Safinya, Phys. Rev. Lett., 1987, 59, 2658-2661.

35 Y. Ouchi, H. Takano, H. Takezoe and A. Fukuda, Jpn. J. Appl. Phys., 1988, 27, 1-7.

36 N. A. Clark, T. P. Rieker and J. E. Mclennan, Ferroelectrics, 1988, 85, 79-97.

37 G. W. Gray and J. W. Goodby, Smectic Liquid Crystals Textures and Structures, Leonard Hill, sgoe and London, 1984.

38 CAChe 3.2, Oxford Molecular Ltd, Oxford, UK, 1999.

39 Identical values were obtained with CPK models.

40 K. Borisch, S. Diele, P. Göring, H. Kresse and C. Tschierske, J. Mater. Chem., 1998, 8, 529-543.

41 B. M. Rosen, C. J. Wilson, D. A. Wilson, M. Peterca, M. R. Imam and V. Percec, Chem. Rev., 2009, 109, 6275-6540.

42 (a) H.-T. Nguyen, C. Destrade and J. Malthete, Adv. Mater., 1997, 9, 375-388; (b) M. Gharbia, A. Gharbi, H. T. Nguyen and J. Malthete, Curr. Opin. Colloid Interface Sci., 2002, 7, 312-325.

43 N. G. Nagaveni, M. Gupta, A. Roy and V. Prasad, J. Mater. Chem., 2010, 20, 9089-9099. 